\title{
Anti-oxidant activity and cytotoxicity of ethanolic extracts from rhizome of Musa acuminata
}

\author{
Kps Adinarayana ${ }^{1 *}$, Ajay P. Babu ${ }^{2}$ \\ ${ }^{1}$ Department of Anatomy, Andhra Medical College, Visakhapatnam, India; *Corresponding Author: kpsanarayana@rediffmaill.com \\ ${ }^{2}$ Bio-Lab, Research Gateway for Biosciences, Visakhapatnam, India; dr.ajay@rgbio.org
}

Received 21 January 2011; revised 20 February 2011; accepted 10 March 2011.

\begin{abstract}
In the present study, antioxidant activities of rhizome of Musa acuminata were investigated. Free radical scavenging assay (DPPH) and reducing power of the ethanolic extract of banana rhizome resulted in potential antioxidant activities. A relatively high percentage of antioxidant activity by DPPH assay $(81.41 \%$ at $200 \mu \mathrm{g} / \mathrm{ml})$ which was comparable to that of the standard, ascorbic acid at $100 \mu \mathrm{g} / \mathrm{ml}$ was observed. With the gallic acid as standard the extract showed a relatively low reductive potential, however, when tested for cytotoxicity at the highest concentration of the tested dose $(256 \mu \mathrm{g} / \mathrm{ml})$, the maximum rate of inhibition observed was $50.32 \%$. The present work indicates that the ethanolic extract of Musa acuminata exhibits significant antiproliferative and antioxidant activities.
\end{abstract}

Keywords: Antioxidant; Antiproliferative; DPPH; Free Radical; MTT Assay

\section{INTRODUCTION}

It has been reported in literature that the role of free radicals in many disease conditions was due to the reactive oxygen species generated from various biochemical reactions [1]. These are capable of damaging crucial biomolecules and have been the major causative factor of many chronic and degenerative diseases including atherosclerosis, diabetes mellitus, cancer, Parkinson's disease and immune dysfunction [2,3]. Primary sources of naturally occurring antioxidants are whole grains, fruits and vegetables. Plant source food antioxidants like vitamin $\mathrm{C}$, vitamin $\mathrm{E}$, carotnenes, phenolic acids, phytate and phytoestrogens have been recognized as having the potential to reduce risk. Moreover, antioxidants from natural sources such as medicinal plants and vegetables have shown to protect against oxidative stress [4]. Compounds such as gallates, have strong antioxidant activity, while others such as the mono-phenols are weak antioxidants. Phenolic compounds, in particular, which are widely distributed in many fruits, vegetables and medicinal plants accounted for their antioxidant capacity of many plants [5].

Antioxidants play major role in neutralizing the effects of free radicals and are known to be effective in preventing the free radical formation by scavenging or promotion of their decomposition [6]. Free radicals present in the biological system which may oxidize nucleic acids, proteins, lipids or DNA are entrapped by the antioxidant compounds like phenolic acids, peroxide, hydroperoxide or lipid peroxyl inhibiting the oxidative mechanism that lead to degenerative diseases $[7,8]$

Different methods published in the literature for the determination of antioxidant activity of foods involve electron spin resonance (ESR) and chemiluminiscence methods. These methods measure the free radical-scavenging activity of antioxidants against free radicals like the 1,1-diphenyl-2-picry;hydrazyl (DPPH) radical, the superoxide anion $(\mathrm{O} 2)$, the hydroxyl radical $(\mathrm{OH})$, or the peroxyl radical (ROO). The malondialdehyde (MDA) or thiobarbituric acid-reactive-substance (TBARS) assays [7] have been used extensively since the 1950's to estimate the peroxidation of lipids in membrane and biological systems. The ABTS [2,2'-azinobis (3-ethylbenzothiazoline-6-sulfonic acid)] radical cation [8] has been used to screen the relative radical-scavenging abilities of flavonoids and phenolics [9]. Vinson et al. have measured phenoilics in fruits and vegetables calorimetrically using the Folin-Ciocalteau reagent and determined their antioxidant capacity by inhibition of low density lipoprotein oxidation mediated by Cupric ions [10].

In the present study, we investigated the antioxidant and anticancer activities of the crude extracts of rhizome of Musa acuminata. 


\section{MATERIALS AND METHODS}

\subsection{Plant Material}

The rhizome of Musa acuminata was collected from local farm in Visakhapatnam. The material was cleaned, washed, dried and carefully powdered.

\subsection{Chemicals}

Folin-Ciocalteu reagent, Trichloroacetic acid (TCA) and ascorbic acid were purchased from Merck, Mumbai, India. Butylated hydroxytoluene (BHT) was purchased from Sigma Chemical Co. (USA). 1, 1-diphenyl-2picrylhydrazyl (DPPH), Gallic acid and MTT (3-(4, 5-dimethylthiazol-2-yl)-2, 5-diphenyltetrazoliumbromide) were obtained from $\mathrm{Hi}$ Media Laboratories Pvt. Ltd, Mumbai, India.

\subsection{Extraction}

Fresh rhizomes of Musa acuminata were dried under shade and the dried material was powdered using mortar and pestle. Ten grams of the powder was packed in filter paper and introduced in the extraction unit of Soxhlet extractor and extracted with ethanol for $48 \mathrm{~h}$. The extract was concentrated and subjected to anti-cancer and antioxidant activities.

\subsection{Determination of the DPPH Scavenging Activity}

1, 1-Diphenyl-2-picrylhydrazyl free radical scavenging assay (DPPH) was carried out according to the following procedure [11]. One $\mathrm{ml}$ of ethanolic extracts of rhizome and standard (Ascorbic acid) at various concentrations $(10,50,100,150$ and $200 \mu \mathrm{g} / \mathrm{ml})$ were added to $3 \mathrm{ml}$ of $0.004 \%$ DPPH in ethanol and the reaction mixture was shaken vigorously. These solution mixtures were kept in dark for $30 \mathrm{~min}$ and optical density was measured at $517 \mathrm{~nm}$ using LT-29 labtronics spectrophotometer. Ethanol with DPPH was used as blank. The \% scavenging activity was calculated using the formula:

Percentage of inhibition of DPPH activity $=\frac{A-B}{A} \times 100$

where $A=$ optical density of the blank and $B=$ optical density of the sample.

\subsection{Determination of Reducing Power}

Reducing power of the extract was determined as reported [12]. The rhizome extract $(10,50,100,150$ and $200 \mu \mathrm{g} / \mathrm{ml}$ ) was mixed with $2.3 \mathrm{ml}$ of phosphate buffer $(0.2 \mathrm{M}, \mathrm{pH} 6.6)$ and $2.5 \mathrm{ml}$ of $1 \%$ potassium ferricyanide $\mathrm{K} 3[\mathrm{Fe}(\mathrm{CN}) 6]$. The mixture was incubated at $37^{\circ} \mathrm{C}$ for 20 min. $10 \%$ Trichloroacetic acid $(2.5 \mathrm{ml})$ was added to the mixture and centrifuged for $10 \mathrm{~min}$ at $1000 \mathrm{rpm}$; the supernatant $(2.5 \mathrm{ml})$ was mixed with $2.5 \mathrm{ml}$ of distilled water and $0.5 \mathrm{ml}$ of $0.1 \% \mathrm{FeCl}_{3}$. After standing for 10 min, the absorbance was measured at $700 \mathrm{~nm}$. High absorbance of the reaction mixture indicates high reducing power. All experiments were repeated at least three times.

\subsection{Cancer Cell Culture}

Carcinoma of cervix (HeLa) cells were maintained in Dulbecco's modified Eagles medium (DMEM) supplemented with $4.5 \mathrm{~g} / \mathrm{L}$ glucose, $2 \mathrm{mM}$ L-glutamine and $5 \%$ fetal bovine serum (FBS) (growth medium) at $37^{\circ} \mathrm{C}$ in $5 \% \mathrm{CO}_{2}$ incubator.

\subsection{MTT Assay}

The MTT assay developed by Mosmann [13] was modified and used to determine the inhibitory effects of test compounds on cell growth in vitro. In brief, the trypsinized cells from T-25 flask were seeded in each well of 96-well flat-bottomed tissue culture plate ${ }^{2}$ at a density of $5 \times 10^{3}$ cells/well in growth medium and cultured at $37^{\circ} \mathrm{C}$ in $5 \% \mathrm{CO}_{2}$ to adhere. After $48 \mathrm{hr}$ incubation, the supernatant was discarded and the cells were pretreated with growth medium and were subsequently mixed with different concentrations of extract $(2,4,8$, $16,32,64,128$ and $256 \mu \mathrm{g} / \mathrm{ml}$ ) in triplicates to achieve a final volume of $100 \mu \mathrm{l}$ and then incubated for $48 \mathrm{hr}$. The extract was prepared as $2.0 \mathrm{mg} / \mathrm{ml}$ concentration stock solutions in dimethyl sulfoxide (DMSO). The final concentration of DMSO in the culture was within $0.2 \%$. Culture medium and solvent were used as controls. Each well then received $5 \mu \mathrm{l}$ of fresh MTT $(0.5 \mathrm{mg} / \mathrm{ml}$ in PBS $)$ followed by incubation for $2 \mathrm{hr}$ at $37^{\circ} \mathrm{C}$. The supernatant growth medium was removed from the wells and replaced with $100 \mu \mathrm{l}$ of DMSO to solubilize the colored formazan product. After $30 \mathrm{~min}$ incubation, the absorbance (OD) was read at a wavelength of $570 \mathrm{~nm}$ on an ELISA reader, Anthos 2020 spectrophotometer.

\section{RESULTS AND DISCUSSION}

The results of the DPPH scavenging activity of the extract (Figure 1) shows that it possesses relatively high percent antioxidant activity $(81.41 \%$ at $200 \mathrm{~g} / \mathrm{ml})$ which was comparable to that of the standard, ascorbic acid at $100 \mu \mathrm{g} / \mathrm{ml}$. All concentrations of the studied extract demonstrated a dose-dependent DPPH radical scavenging activity.

The results of the reductive potential (Figure 2) of the extract and that of the gallic acid standard showed that the ethanolic extract of banana rhizome possess a rela- 


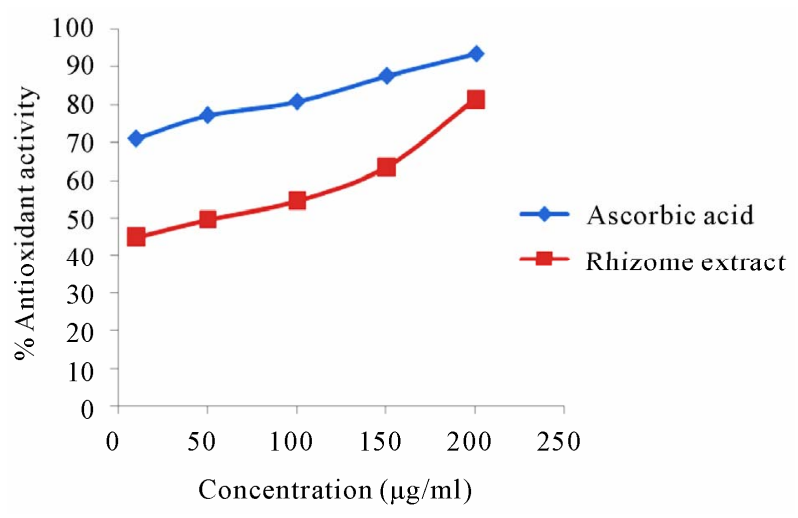

Figure 1. DPPH radical scavenging activity of ethanolic extract of banana rhizome as compared to the standard Ascorbic acid.

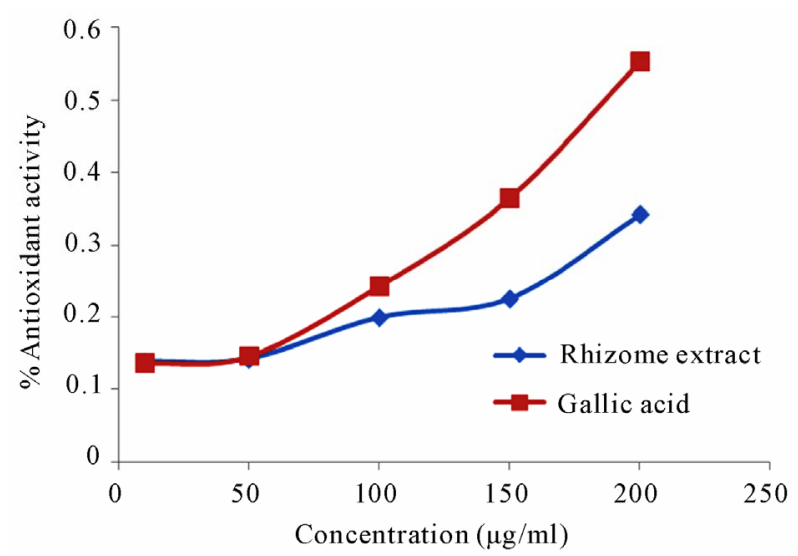

Figure 2. Reducing power of ethanolic extract of banana rhizome as compared to Gallic acid.

tively low reductive potential than the standard. This indicates that the reducing capacity of rhizome may serve as an indicator of its potential antioxidant activity.

\subsection{MTT Assay}

Mean OD values of the extract was corrected by subtracting with the mean OD of blanks. Relative percent inhibition activity is expressed as:

\%inhibition $=100-($ corrected mean OD of sample $\times$ 100/corrected mean OD of control)

A gradual decrease in the viability of HeLa cells was observed in a dose-dependent manner (Table 1 and Figure 3). At the highest concentration of the tested dose $(256 \mu \mathrm{g} / \mathrm{ml})$, the maximum rate of inhibition observed was $50.32 \%$. The morphology of the cells treated with the extract appeared significantly different when compared to untreated control cells, which could probably due to the growth inhibitory and cell death initiating ability of the studied ethanolic extract of banana rhizome.
Table 1. Optical Density (OD) and inhibitory data of ethanolic extract of banana rhizome at various concentrations.

\begin{tabular}{ccccc}
\hline $\begin{array}{c}\text { Cpd conc. } \\
(\mu \mathrm{g} / \mathbf{m l})\end{array}$ & $\begin{array}{c}\text { Observed } \\
\text { OD }^{\mathbf{a}}\end{array}$ & $\begin{array}{c}\text { corrected } \\
\text { OD }^{\mathbf{b}}\end{array}$ & \% viability $^{\mathbf{c}}$ & \% $^{\text {inhibition }}{ }^{\mathbf{d}}$ \\
\hline 2 & 0.853 & 0.803 & 89.88 & 10.12 \\
4 & 0.817 & 0.767 & 85.85 & 14.15 \\
8 & 0.783 & 0.733 & 82.12 & 17.88 \\
16 & 0.738 & 0.688 & 77.08 & 22.92 \\
32 & 0.660 & 0.610 & 68.31 & 31.69 \\
64 & 0.580 & 0.530 & 59.35 & 40.65 \\
128 & 0.505 & 0.455 & 50.95 & 49.05 \\
256 & 0.494 & 0.444 & 49.68 & 50.32 \\
\hline
\end{tabular}

${ }^{\mathrm{a}}$ Mean of triplicates, OD at $570 \mathrm{~nm} ;{ }^{\mathrm{b}}$ Corrected $\mathrm{OD}=$ observed - blank OD Blank OD: 0.05 , Control OD: $0.893 ;{ }^{c_{0}} \%$ viability $=$ corrected OD of sample $\times 100 /$ control OD of cell culture; ${ }^{\mathrm{d}} \%$ inhibition $=100-\%$ viability.

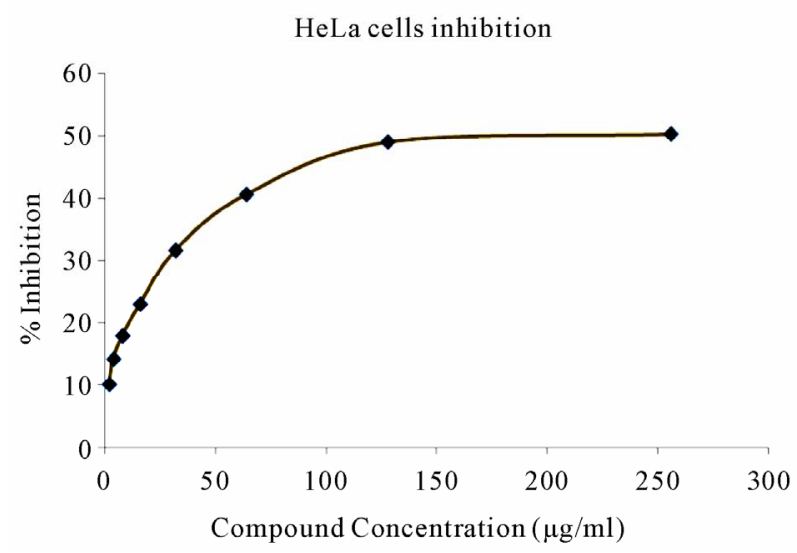

Figure 3. Dose-response curve of the given sample on the growth of HeLa cells cultured in vitro.

\section{CONCLUSIONS}

The studied ethanolic extract of banana rhizome has relatively low reducing power and moderate DPPH radical scavenging activity. However, an increase in dose-dependent treatment of extracts when exposed to carcinoma of cervix (HeLa) cells was observed. The results reported in this paper suggest that the ethanolic extract of banana rhizome could be helpful in addition to the basic medicine in treatment of a few diseases. Further works are needed to be carried out to isolate, identify and characterize the potential antioxidant or antiproliferative compound(s) in the extract for potential clinical use.

\section{REFERENCES}

[1] Halliwell, H. (1994) Free radicals, antioxidants and human disease: Curiosity, cause or consequence? Lancet, 
334, 1994, 721-724.

doi:10.1016/S0140-6736(94)92211-X

[2] Young, I.S. and Woodside, J.V. (2001) Antioxidants in health and disease. Journal of Clinical Pathology, 54, 2001, 176-186. doi:10.1136/jcp.54.3.176

[3] Pourmorad, F., Hosseinimehr, S.J. and Shahabimajd, N. (2006) Antioxidant activity, phenol and flavonid contents of some selected Iranian medicinal plants. African Journal of Biotechnology, 5, 1142-1145.

[4] Cao, G., Sofic, E.R. and Prior, R.L. (1996) Antioxidant capacity of tea and common vegetables. Journal of $\mathrm{Ag}$ riculture and Food Chemistry, 44, 3426-3431. doi:10.1021/jf9602535

[5] Kaur C. and Kapoor, H.C. (2002) Antioxidant activity and total phenolic content of some Asian vegetables. International Journal of Food Science \& Technology, 37, 153-162. doi:10.1046/j.1365-2621.2002.00552.x

[6] Maxwell, S.R.J., (1995) Prospects for the use of antioxidant therapies. Drugs, 49, 345-361. doi:10.2165/00003495-199549030-00003

[7] Dykes, L. and Rooney, L.W. (2007) Phenolic compounds in cereal grains and their health benefits. Cereal Foods World, 52, 105-111.

[8] Miller, H.E., Rigelhof, L.M., Prakash, A. and Kanter, M.A. (2000) Antioxidant content of whole grain break- fast cereals, fruits and vegetables. Journal of the American College of Nutrition, 19, 312-319.

[9] Prior, R., Cao, G., Martin, A., Sofic, E., McEwen, J., O'Brien, C., Lischner, N., Ehlenfeldt, M., Kalt, W., Krewer, G. and Mainland, C.M. (1998) Antioxidant capacity as influenced by total phenolic and anthocyanin content, maturity, and variety of vaccinium species. Journal of Agricultural and Food Chemistry, 46, 26862693. doi:10.1021/jf980145d

[10] Vinson, J.A., Hao, Y., Su, X. and Zubik, L. (1998) Phenol antioxidant quantity and quality in foods: vegetables. Journal of Agricultural Food Chemistry, 46, 3630-3634. doi:10.1021/jf980295o

[11] Nooman, A.K., Ashok, K.S., Atif, A., Zaha, E. and Husni, F. (2008) Antioxidant activity of some common plants. Turkish Journal of Biology, 32, 51-55.

[12] Habila, J.D., Bello, I.A., Dzikwi, A.A., Musa, H. and Abubakar, N. (2010) Total phenolics and antioxidant activity of Tridax procumbens Linn. African Journal of Pharmacy and Pharmacology, 4, 123-126.

[13] Mosmann, T. (1983) Rapid colorimetric assay for cellular growth and survival: Application to proliferation and cytotoxicity assays. Journal of Immunological Methods, $\mathbf{6 5}$, 55. doi:10.1016/0022-1759(83)90303-4 